\title{
Smoke-free legislation and neonatal and infant mortality in Brazil: longitudinal quasi- experimental study
}

\author{
Thomas Hone (1) , ${ }^{1}$ Andre Salem Szklo, ${ }^{2}$ Filippos T Filippidis (1) , ${ }^{1}$ Anthony A Laverty, \\ Isabela Sattamini, ${ }^{3}$ Jasper V Been, ${ }^{4,5,6,7}$ Cristiane Vianna, ${ }^{8}$ Mirian Souza, ${ }^{2}$ \\ Liz Maria de Almeida, ${ }^{2}$ Christopher Millett ${ }^{1,3}$
}

\begin{abstract}
- Additional material is published online only. To view please visit the journal online (http://dx.doi.org/10.1136/ tobaccocontrol-2019-054923).

For numbered affiliations see end of article.
\end{abstract}

\section{Correspondence to}

Dr Thomas Hone, Department of Primary Care and Public Health, Imperial College London SW7 2AZ, London, UK;

thomas.hone12@imperial.ac.uk

Received 3 January 2019 Revised 23 March 2019 Accepted 8 April 2019 Published Online First 31 May 2019

\section{Check for updates}

(c) Author(s) (or their employer(s)) 2020. No commercial re-use. See rights and permissions. Published by BMJ.

To cite: Hone T, Szklo AS, Filippidis FT, et al. Tob Control 2020;29:312-319.

\section{ABSTRACT}

Objective To examine the associations of partial and comprehensive smoke-free legislation with neonatal and infant mortality in Brazil using a quasi-experimental study design.

Design Monthly longitudinal (panel) ecological study from January 2000 to December 2016.

Setting All Brazilian municipalities $(n=5565)$.

Participants Infant populations.

Intervention Smoke-free legislation in effect in each municipality and month. Legislation was encoded as basic (allowing smoking areas), partial (segregated smoking rooms) or comprehensive (no smoking in public buildings). Associations were quantified by immediate step and longer term slope/trend changes in outcomes. Statistical analyses Municipal-level linear fixedeffects regression models.

Main outcomes measures Infant and neonatal mortality.

Results Implementation of partial smoke-free legislation was associated with a $-3.3 \%(95 \% \mathrm{Cl}$ $-6.2 \%$ to $-0.4 \%$ ) step reduction in the municipal infant mortality rate, but no step change in neonatal mortality. Comprehensive smoke-free legislation implementation was associated with $-5.2 \%(95 \% \mathrm{Cl}-8.3 \%$ to $-2.1 \%)$ and $-3.4 \%(95 \% \mathrm{Cl}-6.7 \%$ to $-0.1 \%)$ step reductions in infant and neonatal mortality, respectively, and $\mathrm{a}-0.36(95 \% \mathrm{Cl}-0.66$ to-0.06) annual decline in the infant mortality rate. We estimated that had all smoke-free legislation introduced since 2004 been comprehensive, an additional 10091 infant deaths (95\% CI 1196 to 21761 ) could have been averted.

Conclusions Strengthening smoke-free legislation in Brazil is associated with improvements in infant health outcomes-particularly under comprehensive legislation. Governments should accelerate implementation of comprehensive smoke-free legislation to protect infant health and achieve the United Nation's Sustainable Development Goal three.

\section{INTRODUCTION}

Secondhand smoke (SHS) causes 880000 deaths globally each year, representing 23.8 million disability-adjusted life years (DALYs). ${ }^{1}$ Nearly a quarter of these DALYs are among children under 14 years old. ${ }^{1}$ Comprehensive smoke-free legislation (SFL), which prohibits smoking in enclosed public places, reduces SHS exposure in children and adults and may reduce smoking prevalence, including during pregnancy. ${ }^{2-4}$ Harmful chemicals in SHS can negatively affect fetal development and increase the risk of preterm birth and low birth weight, and infant SHS exposure can increase the risk of sudden infant death syndrome (SIDS) and poor health such as lower respiratory tract infections and asthma. ${ }^{5}$ Evidence shows SFL may improve child health, including reducing preterm births, stillbirths/perinatal mortality, hospital admissions for asthma and lower respiratory tract infections. ${ }^{26-10}$

There is little evidence however on whether implementation of SFL will support achievement of Sustainable Development Goal (SDG) 3's target of reducing neonatal mortality in low and middleincome countries (LMICs). ${ }^{10} 11$ This is important given that smoking rates and exposure to SHS is often high ${ }^{12}$ and implementation of tobacco control policies is typically poor in these settings. One-third of LMIC countries are not expected to meet SDG targets on neonatal mortality. ${ }^{13}$ There is also a need to compare health impacts derived from partial and comprehensive SFLs. This is an important knowledge gap as only $20 \%$ of the global population is covered by comprehensive SFLs. ${ }^{13}$ Partial bans are aggressively promoted by the tobacco industry and typically allow smoking areas in hospitality venues with ventilation systems which are ineffective in eliminating SHS exposure. ${ }^{14-17}$ Previous studies have focused exclusively on high-income settings and have had methodological weaknesses due to SFL being introduced nationally, limiting the ability to use comparator populations. ${ }^{2}$ 6-10 18

Brazil provides an internationally important setting for evaluating SFL. The country has a high infant mortality rate relative to other middleincome countries (14.5 infant deaths per 1000 live births in 2014 (comparable to 14.0 in Colombia, 13.2 in Mexico, 10.0 in China and 7.8 in Russia) ${ }^{19} 20$ but is a recognised global leader in tobacco control with declines in smoking prevalence from $34.8 \%$ in $1989^{21}$ to $14.7 \%$ in $2013 .^{22}$ Strengthening of SFL occurred in a phased manner across Brazilian states and municipalities, followed by a comprehensive federal law in 2014, permitting robust evaluation (box 1; figure 1; see online supplementary appendix figure A1). This study exploits this natural experiment to examine changes in neonatal and infant mortality associated with strengthening SFL in Brazil over the period 2000-2016. As the relationship between SFL and infant health can be mediated through either SHS exposure (of pregnant women 


\section{Box 1 Federal smoke-free legislation in Brazil}

\section{6}

- Law 9294 prohibits the use of cigarettes (and other smoking products whether or not derived from tobacco) in all collective/public enclosures except in areas solely designated for smoking that are isolated and ventilated. Public offices, hospitals, clinics, classrooms, libraries, public/collective workplaces, theatres and cinemas are specifically mentioned as covered by this law.

- Decree 2018 regulates law 9294 and clarifies that bars and restaurants are included, but open-air sites (even if partially enclosed) are exempt. Collective workplaces are defined as workplaces that are intended for use by multiple people at the same time. Smoking areas are required to be exclusively for smokers, separate and should be adequately ventilated. 2000

- Smoking is banned on aircraft and public transport (Law 10 167)

2011

- Law 12546 amends Law 9294 (1996) removing exemptions and completely prohibiting smoking in all closed collective/ public enclosures. 'Collective enclosures' are defined as closed places with public access that are intended for use by multiple people at the same time. However, the law would not be implemented until 2014.

2014

- Decree 8262 defines collective places as public or private places which are accessible to the public or are for shared use, and that are either permanently or temporarily, totally or partially closed on any sides by walls, partitions, a roof or awnings. It also implements Law 12546 in December 2014.

or infants) or smoking during pregnancy, ${ }^{23}$ associations between SFL and self-reported SHS exposure and smoking during pregnancy were also examined using telephone survey data.

\section{METHODS}

Two main analyses were undertaken to examine the associations with partial and comprehensive SFL in Brazil. In the first, quasiexperimental ecological panel (longitudinal) regression models were used to explore the associations of SFL with neonatal and

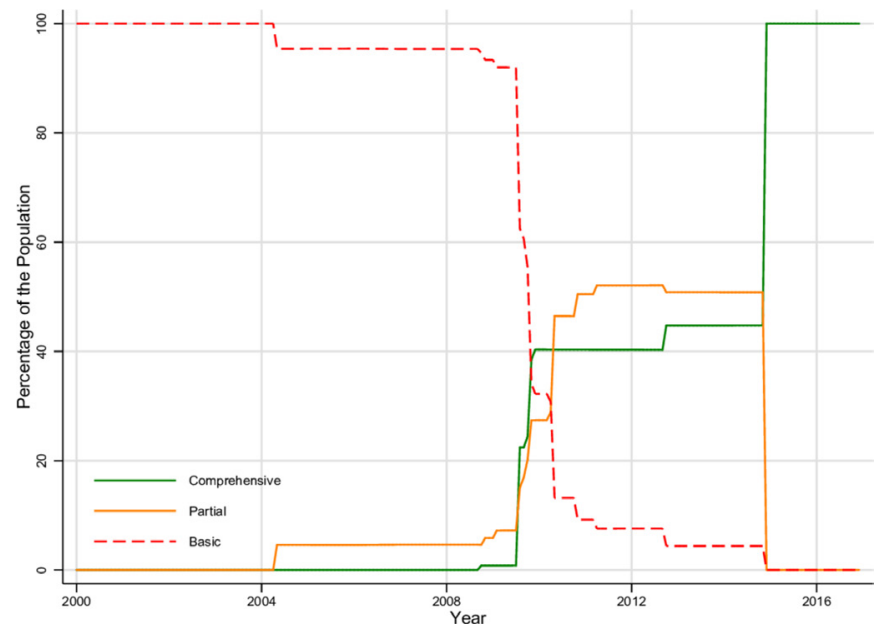

Figure 1 Percentage of theBrazilian population covered by type of smoke-free legislation (2000-2016). infant mortality (primary outcomes) and stillbirths, low birth weight (LBW) and very low birth weight (VLBW) (secondary outcomes) over the period 2000-2016. The unit of analysis was the municipality $(\mathrm{n}=5565)$. In the second, responses from an annual telephone survey (Vigilância de Fatores de Risco e Proteção para Doenças Crônicas por Inquérito Telefônico (VIGITEL)-Telephone Survey of Risk Factors and Chronic Disease Protection) conducted in Brazilian state capitals from 2006 to 2016 were used to determine changes in self-reported exposure to SHS among adults both at home and at work, and smoking during pregnancy.

\section{Data sources}

The first analysis involved compilation of data from multiple public sources. Data on all live births, infant deaths (deaths under 1 year of age), neonatal deaths (deaths within the first 28 days of life) and stillbirths (fetal deaths of 28 weeks or higher gestationWHO definition ${ }^{24}$ ) were obtained for each municipality, month and year (2000-2016) from the Brazilian Ministry of Health website (www.datasus.gov.br). Live birth data provided information on the total number of live births and numbers of VLBW births (less than $1500 \mathrm{~g}$ ), LBW births (less than $2500 \mathrm{~g}$ ), births by caesarean section, births in hospital and births to mothers with at least 4 years of education. While historically underreporting of birth has been problematic in Brazil, in recent years this has improved with over $95 \%$ of birth registered in $2015 .{ }^{25}$ Information on municipal monthly primary healthcare coverage (the Family Health Strategy) was taken from the Brazilian Ministry of Health's Department of Primary Care website (http://dab. saude.gov.br). The Brazilian Institute of Geography and Statistics website (www.ibge.gov.br) provided municipal-level data on population size, poverty rate, cigarette prices and percentage of households without electricity (more details below).

For the second analysis, survey responses were collated from a telephone survey (VIGITEL). These were obtained from the Brazilian Ministry of Health's Department of Health Surveillance website (http://svs.aids.gov.br/download/Vigitel/) for the years 2006-2016. The telephone survey is carried out annually in all state capitals $(\mathrm{n}=27)$ (thus is representative to Brazilian cities which have wealthier populations and lower smoking rates $^{26}$ ), with individuals (18 years or older) randomly selected from telephone registries. ${ }^{27}$ Interviewers collect a range of information on smoking and health behaviours, diet and health conditions. Responses are weighted to reflect the likelihood of owning a telephone and to match age and sex profiles of the cities. ${ }^{27}$ Responses were obtained on reported gender, age, race, educational attainment, self-reported pregnancy status, smoking status ('do you smoke?' (yes/no)), city and exposure to SHS at work or home (see online supplementary appendix table A1 for full question wordings). The survey does not distinguish types of employment or indoor/outdoor working environments.

\section{Classification of SFL laws}

The exposure variable for both analyses was municipal SFL status. Data on state and municipal SFL were identified by searching national law databases and individual state and municipality legislative websites (including: https://leismunicipais. com.br, http://www4.planalto.gov.br/legislacao/portal-legis/ legislacao-estadual/legislacoes-estaduais and http://www.actbr. org.br/biblioteca/mapa). Two authors separately searched databases with key words: tabag*, fuma*, cig* tabaco, fumo. Additionally, free text internet searches were carried out looking for synonyms of 'law' and 'smoking' (in Portuguese). 
Two authors reviewed and classified SFL recording applicable locations, type of bans and dates of legislation and implementation. Disagreements were resolved through discussion. SFL was classified as 'basic' if similar to the 1996 law permitting smoking areas (rather than isolated rooms), or only small protections to SHS exposure were made (eg, targeting specific buildings). SFL was coded as 'partial' if smoking was banned in most public areas but allowed exceptions (eg, in bars and restaurants), or if smoking rooms (as opposed to areas) with ventilation were allowed. SFL was deemed 'comprehensive' if smoking was banned in public buildings, including bars and restaurants, and smoking rooms and areas were prohibited. This included the 2014 federal SFL. As only a small proportion (128/5565 (2.3\%)) of municipalities introduced SFL independent of their state's SFL, state laws were used to determine SFL exposure. Discordance between state and municipality SFL was examined in sensitivity analyses (see online supplementary appendix table A9).

\section{Statistical analysis}

For the first analysis, longitudinal linear fixed-effects regression models were employed to assess the associations between changes in SFL and changes in infant health outcomes over the period 2000-2016 (see online supplementary appendices, equation A1). They are popular methods in impact evaluations as they can exploit routinely available data and examine trends over time. ${ }^{2829}$ These models were used to assess changes in outcomes over time within municipalities, while accounting for the varied and phased introduction of SFL and controlling for potential confounders and time trends. Panel regression methods with fixed-effect specifications are akin to difference-in-differences methods, except they include multiple time points for more than two units of analysis. ${ }^{30}$

A database was created of municipal-month-year observations (a data point for each month of the years 2000-2016 for each municipality). Infant and neonatal mortality rates (per 1000 live births) were generated as the primary outcomes. Stillbirth rates (per 1000 births), and the proportions of births that were VLBW and LBW were generated as secondary outcomes. Independent exposure variables were dummy variables denoting relevant SFL type for each municipal-month-year observation (measuring within-month step changes) and also time since SFL introduction (ie, 0, 1, 2, 3, etc months; measuring slope changes). Published law implementation date (as opposed to law creation date) was used to determine relevant SFL (basic, partial or comprehensive) for municipality-month-year observation. Covariates employed were: percentage of births by caesarean section, percentage of births in hospital, percentage of births to mothers with at least 4 years of education, poverty rate (percentage of population with per capita income of $<\$ R 140$ a month), percentage of households without electricity, Family Health Strategy coverage and annual mean prices of cigarettes (\$Rs) in the state. These covariates were selected as proxies for potential confounders (eg, education, poverty, access to healthcare, risk factors) based on theoretical justifications and published literature.

Models were adjusted for year and month time trends (both non-linear (polynomial)) to account for seasonality in outcomes and underlying trends over the study period. Fixedeffects specifications were employed to control for unobserved time-invariant differences between municipalities. Hence, only within-municipality changes are reported (rather than any differences between municipalities). Cluster-robust SEs were employed to adjust for potential heteroskedasticity and autocorrelation. ${ }^{31}$ Models were weighted by average number of births per municipality over the study period to ascertain effect sizes in relation to the average birth rather than average municipality.

Relative effect sizes were calculated from the weighted values of mean municipal outcome variables the month prior to SFL implementation. Step-change effect sizes were divided by this mortality rate to obtain percentage changes. Additionally, using postregression prediction, municipal mortality rates were predicted under counterfactual scenarios of no SFL implementation, all SFL introduced was partial (both state and federal), and all SFL introduced was comprehensive. These mortality rates were used to calculate estimated numbers of adverted deaths and were rounded (to the nearest integer) at the municipal level before summing nationally.

Inequalities of SFL effects on primary outcomes were explored through stratification of municipalities (into three terciles) by municipal education and poverty rates (municipallevel means overt study period). These groupings were: (1) the mean percentage of births to mothers with four or more years of education (T1 (lowest) mean 79.6\%; T2 85.1\%; T3 (highest) 93.0\%) and (2) mean poverty rate (T1 (highest) mean 48.8\%; T2 22.7\%; T3 (lowest) 7.5\%).

As sensitivity analyses, models were repeated with alternative specifications including random-effects and without weighting, covariates, municipal time-trends or robust SEs. Other analyses included lagged effects and preuptake trends to test for potential endogeneity of intervention, testing a date of SFL implementation as 3 years prior as a check for spurious correlations and reducing the time period of analysis to assess the effect of underlying time trends.

In the second analysis, responses from VIGITEL telephone surveys for 2006-2016 were collated, with individuals as the unit of analyses. Independent variables were categorised: gender (male; female), age (18-24 years; 25-34 years; 35-44 years; 45-54 years; 55-64 years; 65 + years), race/skin colour (white; black/pardo/mixed; yellow (Asian); indigenous/other) and years of education (0-8 years; $9-11$ years; 12 or more years). Mean annual state cigarette price (\$Rs) was also included as an independent variable. Dependent variables were current pregnant smoker (yes; no) and for non-smokers from 2009 onwards (when these questions were available), SHS exposure at home (yes; no) and SHS exposure at work (yes; no). The variable of interest was SFL with date and city of survey used to determine SFL in force.

Logistic regression models were employed to examine likelihood of SHS exposure at home and SHS exposure at work (for non-smokers) and smoking while pregnant. In addition to variables noted above, models were adjusted for year dummies and city fixed effects and survey weights employed.

Stata V.13 software was used for analysis.

Ethical approval for this study was granted by Imperial College's Research Ethics Committee.

\section{RESULTS}

\section{State smoke-free legislation}

Of the 26 states and one federal district of Brazil, all but three (Acre, Piauí, and Rio Grande do Norte) strengthened SFL prior to federal SFL implemented in 2014 (figure 1; see online supplementary appendix table A2). Nine states introduced comprehensive SFL, while 17 introduced partial SFL. One state (Mato Grosso do Sul) introduced partial and later comprehensive SFL. Other laws were identified but classified as basic (no substantial strengthening of the 1996 law) as many covered select public places (eg, healthcare facilities, banks or public offices). The 
Table 1 Results from fixed-effect panel regression models on municipal infant and neonatal mortality, stillbirths and low and very-low birth weight (2000-2016)

\begin{tabular}{|c|c|c|c|c|c|}
\hline & $\begin{array}{l}\text { Infant Mortality } \\
(95 \% \mathrm{Cl})\end{array}$ & $\begin{array}{l}\text { Neonatal Mortality } \\
(95 \% \mathrm{Cl})\end{array}$ & Stillbirth Mortality $(95 \% \mathrm{CI})$ & Low birth weight $(95 \% \mathrm{Cl})$ & $\begin{array}{l}\text { Very-low birth weight } \\
(95 \% \mathrm{Cl})\end{array}$ \\
\hline $\begin{array}{l}\text { Average annual } \\
\text { trend }\end{array}$ & $\begin{array}{l}-0.585^{* * *} \\
(-0.846 \text { to }-0.323)\end{array}$ & $\begin{array}{l}-0.349 * * * \\
(-0.553 \text { to }-0.145)\end{array}$ & $\begin{array}{l}-0.095 \\
(-0.224 \text { to } 0.033)\end{array}$ & $\begin{array}{l}0.032 \\
(-0.011 \text { to } 0.075)\end{array}$ & $\begin{array}{l}0.002 \\
(-0.012 \text { to } 0.016)\end{array}$ \\
\hline \multicolumn{6}{|l|}{ Partial SFL } \\
\hline Step-change & $\begin{array}{l}-0.528^{*} \\
(-0.990 \text { to }-0.066)\end{array}$ & $\begin{array}{l}-0.180 \\
(-0.524 \text { to } 0.163)\end{array}$ & $\begin{array}{l}-0.033 \\
(-0.242 \text { to } 0.177)\end{array}$ & $\begin{array}{l}-0.052 \\
(-0.104 \text { to } 0.001)\end{array}$ & $\begin{array}{l}-0.042 * * * \\
(-0.062 \text { to }-0.022)\end{array}$ \\
\hline Trend-change & $\begin{array}{l}-0.120 \text { * } \\
(-0.216 \text { to }-0.023)\end{array}$ & $\begin{array}{l}-0.089^{*} \\
(-0.166 \text { to }-0.012)\end{array}$ & $\begin{array}{l}-0.019 \\
(-0.067 \text { to } 0.028)\end{array}$ & $\begin{array}{l}-0.032^{* * *} \\
(-0.046 \text { to }-0.018)\end{array}$ & $\begin{array}{l}-0.011^{* * *} \\
(-0.016 \text { to }-0.006)\end{array}$ \\
\hline \multicolumn{6}{|l|}{ Comprehensive SFL } \\
\hline Step-change & $\begin{array}{l}-0.727^{* * *} \\
(-1.157 \text { to }-0.297)\end{array}$ & $\begin{array}{l}-0.330^{*} \\
(-0.651 \text { to }-0.009)\end{array}$ & $\begin{array}{l}0.092 \\
(-0.100 \text { to } 0.284)\end{array}$ & $\begin{array}{l}0.002 \\
(-0.057 \text { to } 0.061)\end{array}$ & $\begin{array}{l}-0.045^{* * *} \\
(-0.069 \text { to }-0.021)\end{array}$ \\
\hline Trend-change & $\begin{array}{l}-0.361^{*} \\
(-0.662 \text { to }-0.059)\end{array}$ & $\begin{array}{l}-0.166 \\
(-0.392 \text { to } 0.059)\end{array}$ & $\begin{array}{l}0.113 \\
(-0.005 \text { to } 0.231)\end{array}$ & $\begin{array}{l}0.062 * * * \\
(0.035 \text { to } 0.090)\end{array}$ & $\begin{array}{l}0.023^{* * *} \\
(0.014 \text { to } 0.032)\end{array}$ \\
\hline $\mathrm{N}$ (Observations) & 1112824 & 1112824 & 1112824 & 1112824 & 1112824 \\
\hline N (Municipalities) & 5565 & 5565 & 5565 & 5565 & 5565 \\
\hline
\end{tabular}

Infant and neonatal mortality expressed as deaths per 1000 live births. Stillbirths per 1000 births. All models adjusted for: proportion of births by caesarean; proportion of births in hospital; proportion of births to mothers with $>4$ years education; proportion of households with no electricity; proportion of population in poverty; family health strategy coverage; state mean price of pack of cigarettes (\$Rs); non-linear year and month time effects and municipal-time trends. Cluster-robust SEs employed.

${ }^{*} \mathrm{P}<0.01 ;{ }^{*} \mathrm{P}<0.005 ;{ }^{*}{ }^{*} \mathrm{P}<0.001$.

$\mathrm{SFL}$, smoke-free legislation.

earliest state legislation was introduced in Pernambuco in 2004 and the latest in Goiás in 2012.

\section{Infant health outcomes}

Over the period 2000-2016, the mean municipal infant mortality rate declined from 24.5 to 13.0 deaths per 1000 live births, while neonatal mortality declined from 15.6 to 9.0 deaths per 1000 live births (see online supplementary appendix table A3 and figures A2-A6). For secondary outcomes, the stillbirth rate declined $21.3 \%$ from 9.6 to 7.6 per 1000 births, while the proportion of births that were LBW and VLBW increased, respectively, from $7.5 \%$ to $8.5 \%$ and from $0.9 \%$ to $1.4 \%$.

The underlying average municipal trend in infant mortality was declining annually by 0.59 (95\% CI CI 0.32 to 0.85 ) deaths per 1000 live births between 2000-2016 (table 1). Neonatal mortality declined annually by 0.35 (95\% CI 0.15 to 0.55 ) deaths per 1000 live births.

Partial SFL was associated with a -0.53 (95\% CI -0.99 to $0.07)$ step reduction in the mean municipal infant mortality rate (table 1). This was a relative reduction of $-3.3 \%(95 \% \mathrm{CI}$ $-6.2 \%$ to $-0.4 \%$ ) given the mean municipal infant mortality rate was 15.9 per 1000 live births in the month prior to partial SFL implementation. There was no associated step change for the neonatal mortality rate. Partial SFL was associated with a faster $-0.12(95 \%$ CI -0.22 to 0.02$)$ annual decline in the infant mortality rate. When combined with the underlying trend, this resulted in an overall annual decline of -0.70 (95\% CI -0.98 to 0.43$)$. Partial SFL was also associated with a $-0.08(95 \%$ CI -0.17 to 0.01 ) annual decline in the neonatal mortality rate (overall a -0.44 annual decline $(95 \%$ CI -0.66 to 0.22$)$ ) in the period following introduction.

Comprehensive SFL was associated with -0.73 (95\% CI -1.16 to 0.30$)$ and $-0.33(95 \% \mathrm{CI}-0.65$ to 0.01$)$ step reductions in infant and neonatal mortality rates, respectively $(-5.2 \%$ (95\% CI $-8.3 \%$ to $-2.1 \%$ ), and $-3.4 \%$ (95\% CI $-6.7 \%$ to $-0.1 \%)$ relative reductions-based on mean municipal infant and neonatal mortality rates of 14.0 and 9.8 per 1000 live births, respectively, in the month prior). Comprehensive SFL was associated with -0.36 (95\% CI -0.66 to 0.06$)$ faster annual decline (overall a -0.95 annual decline (95\% CI -1.34 to 0.55$)$ ) in the infant mortality rate.

For secondary outcomes, partial SFL was associated with a -0.04 step reduction ( $95 \%$ CI -0.06 to 0.02 ; relative reduction $-3.9 \%$ ) in the proportion of births that were VLBW (table 1). There were small significant reductions in the annual trends of the percentages of LBW and VLBW following partial SFL introduction. Comprehensive SFL was associated with a -0.05 step reduction in VLBW (95\% CI -0.07 to 0.02 ; relative reduction $-3.7 \%)$. However, comprehensive SFL was also associated with small increases in the percentages of LBW and VLBW births over time $(0.06$ (95\% CI 0.04 to 0.09 ) and 0.02 (95\% CI 0.01 to $0.03)$, respectively, per year), although these effects were sensitive to changing the period of analysis and time specifications in sensitivity analyses (results not shown). There was no association between any SFL and stillbirths.

Analyses stratified by education and poverty rates (table 2) showed a tendency for greater associations of SFL, particularly comprehensive SFL, in municipalities with lower educational attainment and higher poverty rates. For example, comprehensive SFL was associated with a -2.42 step reduction $(95 \% \mathrm{CI}$ -4.11 to 0.74 ) in the infant mortality rate in municipalities with the lowest levels of maternal education and a -1.71 step reduction $(95 \%$ CI -2.77 to 0.64$)$ in municipalities with intermediate levels of maternal education, compared with no significant association in municipalities with the highest maternal education levels. Likewise, comprehensive SFL was associated with -1.88 (95\% CI -3.55 to 0.21 ) and -1.42 (95\% CI -2.47 to 0.38 ) step reductions in the infant mortality rate in municipalities with the highest and intermediate rates of poverty, respectively, compared with no significant association in municipalities with the lowest rates of poverty.

Cumulatively between 2000 and 2016 there were 799389 infant deaths. Strengthening SFL is estimated to have averted 15 068 deaths (95\% CI 2027 to 31 247) over this period, with the majority in the states of São Paulo (6560 deaths; $43.5 \%$ of total) and Rio de Janeiro $(2714 ; 18.0 \%)$-both with large populations and were early implementers of comprehensive SFL (see online supplementary appendix table A4). Under a scenario where all 
Table 2 Results from fixed-effect panel regression models stratified by municipal educational level or municipal poverty rate (2000-2016)

\begin{tabular}{|c|c|c|c|}
\hline & Municipal education level - T1 (lowest) & $\mathrm{T} 2$ & T3 (highest) \\
\hline & Infant Mortality $(95 \% \mathrm{Cl})$ & Infant Mortality $(95 \% \mathrm{Cl})$ & Infant Mortality $(95 \% \mathrm{Cl})$ \\
\hline \multicolumn{4}{|l|}{ Partial SFL } \\
\hline Step-change & $-0.973 *(-1.894,-0.051)$ & $-1.630^{* * *}(-2.576,-0.683)$ & $0.172(-0.257,0.601)$ \\
\hline Trend-change & $-0.181(-0.386,0.025)$ & $-0.115(-0.277,0.047)$ & $-0.063(-0.214,0.088)$ \\
\hline \multicolumn{4}{|c|}{ Comprehensive SFL } \\
\hline Step-change & $-2.423^{* *}(-4.106,-0.741)$ & $-1.708^{* *}(-2.771,-0.644)$ & $-0.038(-0.510,0.434)$ \\
\hline \multirow[t]{2}{*}{ Trend-change } & $0.298(-0.723,1.319)$ & $-0.588^{*}(-1.170,-0.006)$ & $-0.197(-0.553,0.158)$ \\
\hline & Neonatal Mortality $(95 \% \mathrm{Cl})$ & Neonatal Mortality $(95 \% \mathrm{Cl})$ & Neonatal Mortality $(95 \% \mathrm{Cl})$ \\
\hline \multicolumn{4}{|l|}{ Partial SFL } \\
\hline Step-change & $-0.243(-0.885,0.399)$ & $-0.960 * *(-1.686,-0.234)$ & $0.251(-0.103,0.605)$ \\
\hline Trend-change & $-0.114(-0.265,0.036)$ & $-0.138^{*}(-0.272,-0.004)$ & $-0.064(-0.187,0.059)$ \\
\hline \multicolumn{4}{|c|}{ Comprehensive SFL } \\
\hline Step-change & $-0.881(-2.087,0.326)$ & $-1.100^{* *}(-1.851,-0.349)$ & $-0.032(-0.433,0.369)$ \\
\hline \multirow[t]{3}{*}{ Trend-change } & $0.184(-0.509,0.877)$ & $-0.448^{*}(-0.895,0.000)$ & $-0.159(-0.448,0.130)$ \\
\hline & Municipal poverty rate - $\mathrm{T} 1$ (highest) & $\mathrm{T} 2$ & T3 (lowest) \\
\hline & Infant Mortality $(95 \% \mathrm{Cl})$ & Infant Mortality $(95 \% \mathrm{Cl})$ & Infant Mortality $(95 \% \mathrm{Cl})$ \\
\hline \multicolumn{4}{|l|}{ Partial SFL } \\
\hline Step-change & $-0.436(-1.389,0.516)$ & $-1.230^{* *}(-2.017,-0.444)$ & $0.188(-0.345,0.722)$ \\
\hline Trend-change & $-0.011(-0.028,0.006)$ & $-0.008(-0.022,0.007)$ & $-0.004(-0.016,0.009)$ \\
\hline \multicolumn{4}{|c|}{ Comprehensive SFL } \\
\hline Step-change & $-1.876^{*}(-3.547,-0.206)$ & $-1.424^{* *}(-2.469,-0.378)$ & $0.067(-0.254,0.388)$ \\
\hline \multirow[t]{2}{*}{ Trend-change } & $0.040(-0.045,0.125)$ & $-0.029(-0.080,0.021)$ & $0.000(-0.016,0.015)$ \\
\hline & Neonatal Mortality $(95 \% \mathrm{Cl})$ & Neonatal Mortality $(95 \% \mathrm{Cl})$ & Neonatal Mortality $(95 \% \mathrm{Cl})$ \\
\hline \multicolumn{4}{|l|}{ Partial SFL } \\
\hline Step-change & $0.266(-0.378,0.910)$ & $-0.812^{* *}(-1.376,-0.247)$ & $0.287(-0.177,0.751)$ \\
\hline Trend-change & $-0.012(-0.024,0.001)$ & $-0.007(-0.018,0.005)$ & $-0.004(-0.015,0.006)$ \\
\hline \multicolumn{4}{|c|}{ Comprehensive SFL } \\
\hline Step-change & $-0.680(-1.870,0.511)$ & $-0.941 *(-1.701,-0.182)$ & $0.111(-0.159,0.381)$ \\
\hline Trend-change & $0.017(-0.040,0.075)$ & $-0.024(-0.062,0.014)$ & $0.002(-0.011,0.016)$ \\
\hline
\end{tabular}

Municipalities stratified by mean percentage of births to mothers with 4 or more years of education (T1 (lowest), T3 (highest)) or mean municipal poverty rate (T1 (highest), T3 (lowest)). Infant and neonatal mortality expressed as deaths per 1000 live births. All models adjusted for: proportion of births by caesarean; proportion of births in hospital; proportion of births to mothers with $>4$ years education; proportion of households with no electricity; proportion of population in poverty; family health strategy coverage; state mean price of pack of cigarettes (\$Rs); non-linear year and month time effects and municipal time trends. Cluster-robust standard errors employed.

SFL introduced between 2000 and 2016 was comprehensive, an additional 10091 (95\% CI 1196 to 21 761) infant deaths would have been averted (figure 2). The majority of these would have been in the north-east region of Brazil (5223; 51.8\%).

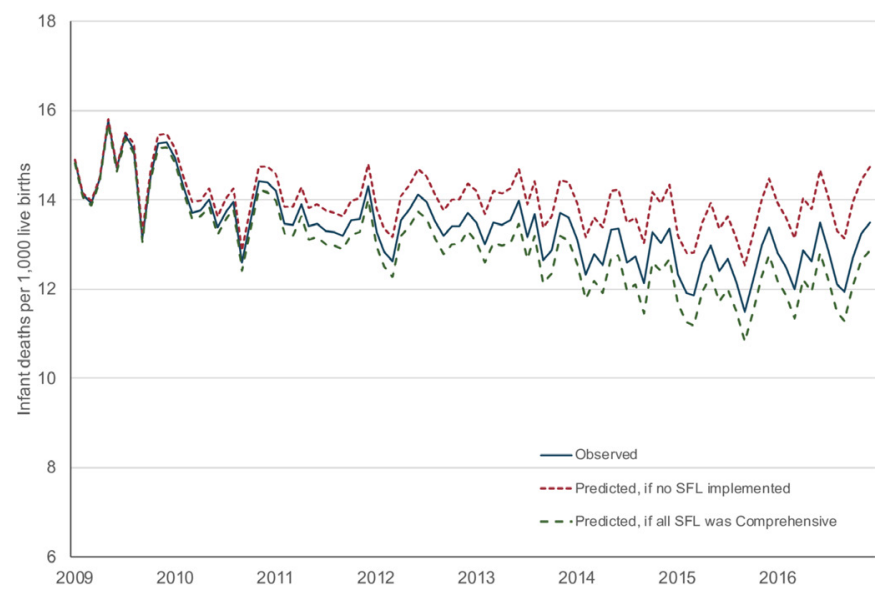

Figure 2 Observed and predicted national infant mortality rate under smoke free legislationscenarios (2009-2016). SFL, smoke-free legislation.
Sensitivity analyses confirmed the robustness of the findings (seeonline supplementary appendix tables A5-A9). Alternative model specifications showed concordant results, suggesting municipal time trends, weighting, robust standard errors and covariates did not explain the findings. Fitting false implementation dates 3 years prior yielded no significant effects, and lags and preuptake trends suggest no pretrends that could be introduce bias. Additionally, analyses exploring municipal SFL that was introduced independently of state SFL revealed no effect of municipal SFL. However, similar findings to the main analysis for state SFL were found, demonstrating that state SFL imparted associated reductions in primary outcomes.

\section{SHS exposure and smoking during pregnancy}

Between 2006 and 2016, there was an average of 53040 (40 853-55 824) respondents to the VIGITEL telephone survey annually, with 158324 respondents surveyed when basic SFL was in force in their city, and 140351 and 273762 respondents, respectively, covered by partial and comprehensive SFL (see online supplementary appendix table A10). Between 2009 and 2016 and between, ${ }^{31} 663$ (11.6\% weighted) and 31667 (11.0\% weighted), non-smokers reported SHS exposure at home and work (see online supplementary appendix figures A7-A8). 
Table 3 Results from logistic regressions on likelihood of SHS exposure at home or work of non-smokers (2009-2016) and likelihood of smoking if pregnant (2006-2016)

\begin{tabular}{|c|c|c|c|c|c|c|}
\hline & \multicolumn{2}{|c|}{ SHS exposure at work } & \multicolumn{2}{|c|}{ SHS exposure at home } & \multicolumn{2}{|c|}{ Smoker, if pregnant } \\
\hline & AOR & $95 \% \mathrm{Cl}$ & AOR & $95 \% \mathrm{Cl}$ & AOR & $95 \% \mathrm{Cl}$ \\
\hline \multicolumn{7}{|l|}{ Smoke-free legislation } \\
\hline Basic & 1 (ref) & & 1 (ref) & & 1 (ref) & \\
\hline Partial & 1.049 & 0.946 to 1.162 & 0.999 & 0.908 to 1.100 & 0.533 & 0.137 to 2.067 \\
\hline Comprehensive & $0.885^{*}$ & 0.804 to 0.974 & 0.990 & 0.905 to 1.084 & $0.212^{*}$ & 0.060 to 0.748 \\
\hline Cigarette price (\$Rs) & $1.045^{*}$ & 1.003 to 1.089 & 0.997 & 0.958 to 1.037 & 2.312 & 0.252 to 21.215 \\
\hline \multicolumn{7}{|l|}{ Gender } \\
\hline Male & 1 (ref) & & 1 (ref) & & 1 (ref) & \\
\hline Female & $0.358^{* * *}$ & 0.341 to 0.376 & $1.173^{* * *}$ & 1.118 to 1.231 & 1 & 1.000 to 1.000 \\
\hline \multicolumn{7}{|l|}{ Race } \\
\hline White & 1 (ref) & & 1 (ref) & & 1 (ref) & \\
\hline Black/Pardo/Mixed & $1.221^{* * *}$ & 1.148 to 1.298 & $1.078^{*}$ & 1.015 to 1.144 & 1.196 & 0.491 to 2.910 \\
\hline Yellow (Asian) & $1.124^{* *}$ & 1.033 to 1.222 & 1.067 & 0.986 to 1.154 & 1.96 & 0.840 to 4.572 \\
\hline Indigenous/Other & $1.351^{* * *}$ & 1.206 to 1.513 & 1.069 & 0.969 to 1.178 & $8.420^{*}$ & 1.112 to 63.769 \\
\hline \multicolumn{7}{|l|}{ Age groups } \\
\hline $18-24$ years & 1 (ref) & & 1 (ref) & & 1 (ref) & \\
\hline $25-34$ years & $1.352^{* * *}$ & 1.248 to 1.464 & $0.702^{* * *}$ & 0.655 to 0.752 & 0.498 & 0.242 to 1.025 \\
\hline $35-44$ years & $1.283^{* * *}$ & 1.184 to 1.390 & $0.417^{* * *}$ & 0.386 to 0.449 & 1.34 & 0.586 to 3.066 \\
\hline $45-54$ years & 1.055 & 0.970 to 1.148 & $0.427^{* * *}$ & 0.395 to 0.462 & $8.469^{* * *}$ & 2.483 to 28.887 \\
\hline 55-64 years & $0.694^{* * *}$ & 0.628 to 0.767 & $0.459^{* * *}$ & 0.421 to 0.500 & 0 & 0 \\
\hline $65+$ years & $0.182^{* * *}$ & 0.159 to 0.208 & $0.374^{* * *}$ & 0.342 to 0.409 & 0 & 0 \\
\hline \multicolumn{7}{|l|}{ Educational level } \\
\hline $0-8$ years & $2.670^{* * *}$ & 2.483 to 2.870 & $1.518^{* * *}$ & 1.417 to 1.627 & $15.590^{* * *}$ & 6.825 to 35.613 \\
\hline 9-11 years & $1.861^{* * *}$ & 1.747 to 1.984 & $1.234^{* * *}$ & 1.164 to 1.309 & $2.626^{*}$ & 1.038 to 6.642 \\
\hline 12 or more years & 1 (ref) & & 1 (ref) & & 1 (ref) & \\
\hline $\mathrm{N}$ (total) & 371714 & & 371714 & & 4016 & \\
\hline
\end{tabular}

Surveys only cover state capitals $(\mathrm{n}=26)$ and the Federal District; estimates weighted to account for likelihood of owning a telephone and to model age-sex distribution of cities; city and year fixed effects also adjusted for but not shown.

${ }^{*} \mathrm{P}<0.01 ;{ }^{*} \mathrm{P}<0.005 ;{ }^{* *} \mathrm{P}<0.001$.

$A O R$, adjusted OR; SHS, secondhand smoke.

Between 2006 and 2016, 147 (5.9\% weighted) out of 4016 pregnant women reporting smoking (see online supplementary appendix figure A9).

In adjusted logistic regression models, non-smoking individuals were 11.4\% less likely (adjusted OR (AOR): 0.89 (95\% CI 0.80 to 0.97$)$ ) to report SHS exposure at work if covered by comprehensive SFL, although there was no significant association with partial SFL (table 3). Neither partial or comprehensive SFL was associated with SHS exposure at home. Pregnant women were substantially less likely to self-report smoking following comprehensive SFL introduction (AOR: 0.21 (95\% CI 0.06 to 0.75 ), while there was no significant association with partial SFL.

\section{DISCUSSION}

In Brazil, the introduction of SFL was associated with significant and important reductions in neonatal and infant mortality. Comprehensive SFL was associated with larger reductions than partial SFL for neonatal mortality (a 3.4\% reduction for comprehensive SFL while non-significant for partial) and infant mortality (5.2\% reduction vs a $3.3 \%$ reduction). Infant health benefits following SFL strengthening were greater in municipalities with high poverty and lower educational levels. Additionally, comprehensive SFL was associated with lower self-reported SHS exposure at work and reduced smoking while pregnant.
This is the first study of early life outcomes in relation to SFL in an LMIC, demonstrating comparable benefits to highincome countries. The study is valuable given the vast majority of smokers live in LMICs where comprehensive SFL remains weak. ${ }^{13}$ It employs robust quasi-experimental methods to elucidate changes over time and exploits a unique natural experiment of SFL implementation in Brazil to examine both partial and comprehensive SFL. A range of sensitive analyses point to the robustness and validity of the findings.

Our findings are highly plausible and consistent with previous research conducted in high-income countries. ${ }^{10}$ Previous research has shown that comprehensive SFL is associated with reduced SHS exposure among children and adults compared with no legislation. ${ }^{231023}$ One previous study found that the introduction of comprehensive SFL in England was associated with lower infant and neonatal mortality. ${ }^{6}$ The lack of association identified here between SFL and stillbirths is similar to a study from the Netherlands (although the SFL was not comprehensive) but contrary to evidence from England which found a reduction following SFL introduction. ${ }^{1023}$ The reductions in VLBW births following partial and comprehensive SFL introduction are conflicting to a recent metaanalysis identifying no association between VLBW and SFL, although the effects identified in this analysis are not far from significance. ${ }^{10}$ Similarly, the lack of association between SFL introduction and LBW births are also contradictory to this 
meta-analysis which did identify reductions in LBW following SFL introduction. ${ }^{10}$ The LMIC context of this study could be a possible explanation for these differences. Regarding the findings of a greater impact of SFL in municipalities with high poverty and lower educational levels, this is likely due to their higher baseline infant mortality rates and higher rates of smoking and SHS exposure. Additionally, the findings of reduced smoking during pregnancy are in line with existing evidence. ${ }^{2}$ Reported smoking prevalence by pregnant women (5.9\%) was lower than national estimates of adult smoking in Brazil $(10.1 \%-15 \%)^{32}$ but quite comparable to other national survey estimates for smoking among pregnant women in 2008 $(7.7 \%)^{33}$ and $2013(4.7 \%) .^{34}$ There may be differences due to wealthier urban populations surveyed and potential for underreporting bias through telephone interviewing, but the comparability of maternal smoking estimates suggest the findings are nationally representative. ${ }^{26}$

There are limitations with this study. First, the main analysis is ecological with aggregate data precluding individual inference, with the possibility of unobserved confounding. However, panel regression models are robust, frequentlyemployed models that account for underlying trends over time. Furthermore, the dataset is constructed with large temporal and spatial variation to maximise granularity of the analysis. Fixed-effects specifications are employed to examine changes within municipalities adjusting for potential time-invariant confounders. Sensitivity analyses further point to the robustness of the findings, although many of the slope changes identified were not very robust which can be a common issue in panel regression models without long postlegislation periods. Second, concurrent interventions or unobserved time-variant confounding (eg, the introduction of other infant healthimproving policies, new healthcare services or improvements in living standards) could represent biases. However, to affect the estimates, they would have to be concurrently introduced with different SFL across all relevant states, which seems unlikely. The outbreak of Zika in Brazil in 2015 may be a potential confounder; however, evidence demonstrates the birth rate did not substantially fall until after April 2016 (16 months after national SFL), and there was no associated changes in fetal mortality. ${ }^{35}$

Third, Brazil has some data challenges-under-reporting of births and deaths and limited covariate data quality. However, data quality has improved substantially in recent years and is less problematic over the period when most SFL was introduced. ${ }^{25}$ Furthermore, model specifications account for trends over time - including gradual improvements in data qualityand there would have to be changes in data recording quality concurrent with the variable introduction of SFL to bias these results. Data limitations restricted other potentially relevant analyses (notably of preterm births as gestational age was recorded in categories until $2011^{34}$ ) and further stratification by socioeconomic groups. Fourth, the averted deaths calculation used predicted mortality rates and rounded at the municipal level. Because the majority of municipalities have few live births, small changes in mortality rates would not have altered overall predicted deaths (ie, 1.1 or 1.4 deaths would both round to 1), making predicted deaths conservative estimates.

Fifth, the second analysis uses data from telephone surveys in Brazilian state capital cities. This limits representativenessboth in terms of geography and socioeconomics (those owning a telephone)-although survey weighting aims to adjust for these. Nonetheless, non-surveyed individuals without a telephone, who are likely to be poorer and less educated, are more likely to be exposed to SHS or smoke during pregnancy ${ }^{36}$ and therefore to be more affected by SFL. Reported exposure to SHS at work from VIGITEL (11.1\% in 2013) was lower than other studies- $13.5 \%$ of urban non-smokers working in closed environments in a 2013 survey. ${ }^{22}$ This difference likely stems from VIGITEL's lack of information on respondents' workplaces (whether indoors or outdoors) and survey representativeness. Additionally, socioeconomic differences may affect representativeness of maternal smoking estimates, although this would not affect the internal validity of the results of this study. Sixth, there may be challenges of recall bias, and SFL may be associated with increased awareness and reporting of SHS exposure. However, this would not undermine effects found in this study and may explain non-significance for exposure to SHS at home. Seventh and lastly, it is possible that SFL compliance was not $100 \%$ in all municipalities. Although there are reports of generally good compliance in large cities, ${ }^{37}$ a lack of compliance may have reduced potential health benefits of SFL, and there could have been heterogeneity in compliance across Brazil.

Brazil has taken bold action on tobacco control and our findings suggest this may have contributed the impressive reductions in neonatal and infant mortality over the last 20 years. ${ }^{38}$ This is against a backdrop of limited progress in tobacco control in other countries and calls for accelerated action. ${ }^{13}$ This study provides the strongest evidence thus far available that tobacco control measures are an important component of policies needed to achieve infant health targets within SDG $3 .^{11}$ This evidence is valuable and timely, given over one-third of countries are currently projected to not meet SDG 3 target's for neonatal mortality by $2030 .{ }^{39}$ Furthermore, this study provides some evidence that these benefits accrued in areas with higher poverty and may then reduce inequalities. Key tobacco control measures, such as SFLs, banning of advertising and promotion and increased taxation are cost neutral or revenue raising and are eminently implementable with political will. Recent framing of tobacco control measures as a child rights issue should provide new impetus for advocates and governments to overcome tobacco industry interference and implement these essential, lifesaving measures. ${ }^{40}$

\section{CONCLUSION}

Introduction of SFL was associated with improvements in infant health in Brazil, with greater benefits from comprehensive SFL. Governments should accelerate implementation of comprehensive SFL to protect infant health and achieve SDG 3.

\footnotetext{
Author affiliations

${ }^{1}$ Department of Primary Care and Public Health, Imperial College London, London, UK

${ }^{2}$ Population Research Division, National Cancer Institute/Ministry of Health Brazil, Rio de Janeiro, Brazil

${ }^{3}$ Center for Epidemiological Research in Nutrition and Health, University of São Paulo, São Paulo, São Paulo, Brazil

${ }^{4}$ Division of Neonatology, Department of Paediatrics, Erasmus MC - Sophia Children's Hospital, University Medical Centre Rotterdam, Rotterdam, The Netherlands

${ }^{5}$ Department of Public Health, Erasmus MC, University Medical Centre Rotterdam, Rotterdam, The Netherlands

${ }^{6}$ Department of Obstetrics and Gynaecology, Erasmus MC, University Medical Centre Rotterdam, Rotterdam, The Netherlands

${ }^{7}$ Usher Institute of Population Health Sciences and Informatics, The University of Edinburgh, Edinburgh, United Kingdom

${ }^{8}$ Tobacco Control Deptartment - Latin America, International Union Against Tuberculosis and Lung Disease (The Union), Paris, France
} 


\section{What this paper adds}

What is already known on this subject

- Second-hand smoke exposure is a large contributor to global mortality and morbidity-especially in children.

- Smoke-free legislation (SFL) has been shown to improve infant health outcomes, although this evidence base is restricted to high-income countries.

- The differential impacts of partial and comprehensive SFL are underexplored.

What important gaps in knowledge exist on this topic

- The introduction of SFL in Brazil is associated with reduction in infant and neonatal mortality, with greater benefits accrued under comprehensive compared with partial legislation.

Contributors CM proposed the original research question which was subsequently developed with input from all authors. JVB and TH contributed to the study design and analytical approach. TH compiled the data with input from IS, JB, ASS and CV. TH carried out the data analysis and production of figures and tables with input from all authors. All authors contributed to the data interpretation. TH wrote the first draft of the manuscript which was revised and edited by all authors.

Funding The authors have not declared a specific grant for this research from any funding agency in the public, commercial or not-for-profit sectors.

Competing interests None declared.

Patient consent for publication Not required.

Provenance and peer review Not commissioned; externally peer reviewed.

Data availability statement Data are available in a public, open access repository. Data are available upon reasonable request.

\section{ORCID iDs}

Thomas Hone http://orcid.org/0000-0003-0703-6973

Filippos T Filippidis http://orcid.org/0000-0002-2101-2559

\section{REFERENCES}

1 Gakidou E, Afshin A, Abajobir AA, et al. Global, regional, and national comparative risk assessment of 84 behavioural, environmental and occupational, and metabolic risks or clusters of risks, 1990-2016: a systematic analysis for the global burden of Disease Study 2016. The Lancet 2017;390:1345-422.

2 Been JV, Nurmatov UB, Cox B, et al. Effect of smoke-free legislation on perinatal and child health: a systematic review and meta-analysis. The Lancet 2014;383:1549-60.

3 Callinan JE, Clarke A, Doherty K, et al. Legislative smoking bans for reducing secondhand smoke exposure, smoking prevalence and tobacco consumption. Cochrane Database Syst Rev 2010;4.

4 Nanninga S, Lhachimi SK, Bolte G. Impact of public smoking bans on children's exposure to tobacco smoke at home: a systematic review and meta-analysis. BMC Public Health 2018;18.

5 Department of Health, Human Services, Centers for Disease Control. The health consequences of involuntary exposure to tobacco smoke: a report of the surgeon General. Atlanta (GA): Centers for Disease Control and Prevention (US), 2012.

6 Been JV, Mackay DF, Millett C, et al. Impact of smoke-free legislation on perinatal and infant mortality: a national quasi-experimental study. Scientific Reports 2015;5.

7 Leonardi-Bee J, Smyth A, Britton J, et al. Environmental tobacco smoke and fetal health: systematic review and meta-analysis. Arch Dis Child Fetal Neonatal Ed 2008;93:F351-61.

8 Boldo E, Medina S, Oberg M, et al. Health impact assessment of environmental tobacco smoke in European children: Sudden infant death syndrome and asthma episodes. Public Health Rep 2010;125:478-87.

9 Flenady V, Koopmans L, Middleton P, et al. Major risk factors for Stillbirth in highincome countries: a systematic review and meta-analysis. Lancet 2011;377:1331-40.

10 Faber T, Kumar A, Mackenbach JP, et al. Effect of tobacco control policies on perinatal and child health: a systematic review and meta-analysis. The Lancet Public Health 2017;2:e420-37.

11 United Nations. Sustainable development goals (SDGs) new York, NY, USA: United Nations, 2018. Available: https://sustainabledevelopment.un.org/sdgs
$12 \mathrm{Ng} \mathrm{M}$, Freeman MK, Fleming TD, et al. Smoking prevalence and cigarette consumption in 187 countries, 1980-2012. JAMA 2014;311:183-92.

13 World Health Organisation. Who report on the global tobacco epidemic. Geneva, Switzerland: World Health Organisation, 2017.

14 World Health Organization, Tobacco Free Initiative. Protection from exposure to second-hand tobacco smoke: policy recommendations. World Health Organization, 2007.

15 Wagner J, Sullivan D, Faulkner D, et al. Environmental tobacco smoke leakage from smoking rooms. J Occup Environ Hyg 2004;1:110-8.

16 Drope J, Bialous S, Glantz S. Tobacco industry efforts to present ventilation as an alternative to smoke-free environments in North America. Tobacco Control 2004;13(suppl 1):i41-7.

17 Nebot M, López MJ, Gorini G, et al. Environmental tobacco smoke exposure in public places of European cities. Tobacco Control 2005;14:60-3.

18 Leonardi-Bee J, Britton J, Venn A. Secondhand smoke and adverse fetal outcomes in nonsmoking pregnant women: a meta-analysis. Pediatrics 2011;127:734-41.

19 The World Bank. DataBank Washington DC, USA: the world bank, 2018. Available: http://data.worldbank.org/ [Accessed 26/06 2018].

20 Victora CG, Aquino EM, do Carmo Leal M, et al. Maternal and child health in Brazil: progress and challenges. The Lancet 2011;377:1863-76.

21 Levy D, de Almeida LM, Szklo A. The Brazil SimSmoke policy simulation model: the effect of strong tobacco control policies on smoking prevalence and SmokingAttributable deaths in a middle income nation. PLoS Med 2012;9:e1001336.

22 Malta DC, Oliveira TP, Vieira ML, et al. Uso e exposição fumaça do tabaco no Brasil: resultados da Pesquisa Nacional de Saúde 2013. Epidemiologia e Serviços de Saúde 2015;24:239-48.

23 Faber T, Been JV, Reiss IK, et al. Smoke-free legislation and child health. NPJ Primary Care Respiratory Medicine 2016;26.

24 World Health Organization. Stillbirths Geneva, Switzerland: the World Health organization, 2018. Available: http://www.who.int/maternal_child_adolescent/ epidemiology/stillbirth/en/ [Accessed 15 July 2018].

25 Lima EEC, Queiroz BL, Zeman K. Completeness of birth registration in Brazil: an overview of methods and data sources. Genus 2018;74.

26 Ferreira AD, César CC, Malta DC, et al. Validity of data collected by telephone survey: a comparison of VIGITEL 2008 and 'Saude em Beaga' survey. Revista Brasileira de Epidemiologia 2011;14:16-30.

27 Bernal RTI, Iser BPM, Malta DC, et al. Surveillance system for risk and protective factors for chronic diseases by telephone Survey (Vigitel): changes in weighting methodology. Epidemiologia e Serviços de Saúde 2017;26:701-12.

28 Hone T, Rasella D, Barreto ML, et al. Association between expansion of primary healthcare and racial inequalities in mortality amenable to primary care in Brazil: a national longitudinal analysis. PLoS Med 2017;14:e1002306.

29 Hone T, Rasella D, Barreto M, et al. Large Reductions In Amenable Mortality Associated With Brazil's Primary Care Expansion And Strong Health Governance. Health Aff 2017;36:149-58.

30 Wooldridge JM. Econometric analysis of cross section and panel data. MIT press, 2010

31 Bertrand M, Duflo E, Mullainathan S. How much should we trust differences-indifferences estimates? Q J Econ 2004;119:249-75.

32 Lange S, Probst C, Rehm J, et al. National, regional, and global prevalence of smoking during pregnancy in the general population: a systematic review and meta-analysis. The Lancet Global Health 2018.

33 Levy D, Jiang M, Szklo A, et al. Smoking and adverse maternal and child health outcomes in Brazil. Nicotine Tob Res 2013;15:1797-804.

34 Szklo AS, Yuan Z, Levy D. Update and extension of the Brazil SimSmoke model to estimate the health impact of cigarette smoking by pregnant women in Brazil. Cad Saúde Pública 2017;33:e00207416.

35 Castro MC, Han QC, Carvalho LR, et al. Implications of Zika virus and congenital Zika syndrome for the number of live births in Brazil. Proceedings of the National Academy of Sciences 2018;115:6177-82.

36 Silveira MF, Matijasevich A, Menezes AMB, et al. Secular trends in smoking during pregnancy according to income and ethnic group: four population-based perinatal surveys in a Brazilian City. BMJ open 2016;6:e010127-e27.

37 Bialous SA, Martins S. Brazil: Sao Paulo takes the lead. Tobacco Control 2009;18:341-4.

38 Paim J, Travassos C, Almeida C, et al. The Brazilian health system: history, advances, and challenges. Lancet 2011;377:1778-97.

39 Abajobir AA, Abate $\mathrm{KH}$, Abbafati $\mathrm{C}$, et al. Measuring progress and projecting attainment on the basis of past trends of the health-related sustainable development goals in 188 countries: an analysis from the global burden of Disease Study 2016. The Lancet 2017;390:1423-59.

40 Toebes B, Gispen ME, Been JV, et al. A missing voice: the human rights of children to a tobacco-free environment. Tobacco control 2018;27:3-5. 